\title{
Determinantes da intensidade tecnológica das exportações estaduais no período de ascensão do preço das commodities
}

\author{
Determinants of the technological intensity of state \\ exports for the period of rising commodity prices
}

FELIPE ORSOLIN TEIXEIRA*

DANIEL ARRUDA CORONEL**

JOSÉ LUIS DA COSTA OREIRO***

RESUMO: O objetivo deste trabalho é analisar o comportamento e os determinantes das exportações dos estados brasileiros, por níveis de intensidade tecnológica, para o período de ascensão nos preços das commodities. Os resultados mostraram que setores de maior tecnologia perderam representatividade nas exportações e que a taxa real de câmbio pode facilitar o acesso de setores estratégicos no mercado internacional.

PALAVRAS-CHAVE: Exportações; intensidade tecnológica; estados brasileiros.

ABSTRACT: The aim of this paper is to analyze the behavior and determinants of Brazilian states exports, by technological intensity levels, for the period of commodity prices shocks. The results showed that sectors of higher technology lost representativeness in exports and that the real exchange rate can facilitate access for strategic sectors in the international market.

KEYWORDS: Exports; technological intensity; Brazilian states.

JEL Classification: F43; R11; C23.

\footnotetext{
* Doutorando em Economia pela Universidade Federal do Rio Grande do Sul (UFRGS), Rio Grande do Sul, RS, Brasil. E-mail: felipeorsolin@gmail.com. Orcid: https://orcid.org/0000-0002-6686-0164.

* Professor Associado do Departamento de Economia e Relações Internacionais da Universidade Federal de Santa Maria (UFSM); Diretor da Editora UFSM e Bolsista de Produtividade do CNPq, Santa Maria, Rio Grande do Sul, RS, Brasil. E-mail: daniel.coronel@uol.com.br. Orcid: https://orcid.org/00000003-0264-6502.

*** Professor Associado do Departamento de Economia da Universidade de Brasília (UNB), Pesquisador nível IB do CNPq, Brasília, DF, Brasil. Pesquisador Associado do Centro de Estudos do Novo-Desenvolvimentismo da FGV-SP, São Paulo, SP, Brasil. E-mail: joreirocosta@yahoo.com.br. Orcid: https:// orcid.org/0000-0001-8955-8868. Submetido: 11/Fevereiro/2019; Aprovado: 5/Outubro/2019.
} 


\section{INTRODUÇÃO}

A melhor "receita" para o alcance do crescimento econômico ainda é algo a ser descoberto por economistas. Na literatura, isso é associado a inúmeros fatores, tais como as origens do processo de colonização, os acúmulos de capital humano, os fatores geográficos, a qualidade das instituições, entre outros.

Após a década de 1990, intensificou-se um debate na literatura internacional sobre a importância de se analisar a dinâmica de crescimento econômico com base no conflito distributivo existente entre salários e lucros (Bhaduri Marglin, 1990). No entanto, destacam-se dois fatores que devem ser levados em conta em uma estratégia de crescimento por meio da maior participação dos salários e do consumo das massas. De um lado, a maior parcela salarial na renda perde eficácia em uma economia que assume maior grau de abertura comercial (Blecker, 2002). Por outro, a eficácia da estratégia de crescimento por meio do consumo das massas depende da estrutura produtiva e da capacidade dessa em atender a uma demanda interna mais sofisticada. Caso contrário, espera-se um vazamento da demanda para as importações e os efeitos sobre o crescimento se tornam reduzidos.

Dessa forma, quando um país esgota suas possibilidades de crescimento via expansão da demanda interna, tem-se que as exportações se tornam o principal componente de expansão da demanda agregada. Essa é a base dos modelos de crescimento export-led, que tem sustentação nos trabalhos de Kaldor (1957), Dixon e Thirlwall (1975) e Thirlwall (1979), mais especificamente no que tange à causação cumulativa entre exportações e crescimento econômico.

A partir de 2003, o Brasil passou por um processo de crescimento bastante influenciado por exportações, principalmente em decorrência da ascensão no índice de preço das commodities ${ }^{1}$. Este cenário colocou a economia brasileira em uma trajetória positiva de crescimento e influenciou para a melhoria em indicadores socioeconômicos, observados, por exemplo, pela diminuição da taxa de desocupação $\left(12,3\right.$ para $\left.5,4 \%^{2}\right)$ e redução no índice de Gini $\left(0,58\right.$ para $\left.0,53^{3}\right)$ entre 2003 e 2013 e aumento na parcela salarial na renda nacional a partir de 2004 (SCN/IBGE ${ }^{4}$, 2020). A melhoria desses indicadores tem efeitos reais sobre a economia, principalmente pela ótica da demanda. Ao mesmo tempo, o boom de commodities gerou efeitos negativos sobre a diversificação da estrutura produtiva (Libanio et al., 2014) e sobre os preços relativos em longo prazo (Bresser-Pereira, 2007; Carneiro, 2012;

\footnotetext{
${ }^{1}$ A recuperação da economia global, a baixa taxa de juros da economia norte-americana e o crescimento da economia chinesa, entre outros fatores, podem ter sido determinantes para a ascensão nos preços das commodities (PRATES, 2007).

${ }^{2}$ Dados com base na Pesquisa Mensal de Emprego (PME/IBGE) para um conjunto de 6 regiões metropolitanas.

${ }^{3}$ Instituto de Pesquisa Econômica Aplicada (IPEA, 2020).

${ }^{4}$ Sistema de Contas Nacionais do Instituto Brasileiro de Geografia e Estatística (SCN/ IBGE).
} 
Serrano, 2014), e isso restringiu a eficácia de uma estratégia de crescimento com maior consumo das massas.

Essa situação destaca a necessidade de o Brasil analisar crescimento como sinônimo de mudança estrutural, a qual deve englobar o processo de industrialização, a diversificação da pauta de exportação e o aumento da elasticidade-renda das exportações ${ }^{5}$. A dinâmica conjunta desses três fatores tende a quebrar com a especialização da estrutura produtiva em atividades nas quais o país detém vantagens comparativas, ou seja, produção e exportação de produtos primários. Caso contrário, o avanço desse processo de especialização gera uma tendência secular de deterioração dos termos de troca em longo prazo, o que intensificaria o processo de desenvolvimento desigual (Rodriguez, 2009).

Também cabe destacar que a mudança estrutural está relacionada com a complexidade e/ou sofisticação produtiva de uma economia, que depende do conhecimento técnico e científico que está embutido nas pessoas (capital humano), nas máquinas e equipamentos (capital físico), e na capacidade das pessoas em se conectarem e assim trocar informações (capital social). Dessa forma, aquilo que uma economia produz e exporta revela a complexidade e/ou sofisticação das suas capacitações produtivas (Hidalgo, 2015).

Também se destaca a importância de analisar as características específicas no local e no tempo (Dugger Sherman, 2000) em um país periférico e com grande extensão territorial, como é o caso de Brasil. No contexto periférico, destaca-se a teoria estruturalista ${ }^{6}$ com as contribuições de Prebisch (1949) sobre deterioração dos termos de troca, as de Furtado no que tange à relação entre cultura e desenvolvimento, e as de Sunkel (1958) com a relação entre inflação e os desequilíbrios de balanço de pagamentos. No contexto territorial, destaca-se a importância de uma análise que inclui as especificidades internas e regionais de um país (Krugman, 1991).

Neste contexto, tem-se por hipótese que uma análise dos fatores relacionados ao desempenho das exportações por níveis tecnológicos pode ajudar a explicar o porquê de o país não ter avançado no processo de mudança estrutural e da falta de sucesso na estratégia de crescimento por meio do consumo das massas. Com isso, este artigo tem por objetivo verificar o comportamento e os determinantes das exportações dos estados brasileiros, por nível de intensidade tecnológica, após o período de boom das commodities.

O artigo utiliza a metodologia system GMM para as estimações e apresenta importantes contribuições. A primeira diz respeito à utilização de dados de exportações desagregados por unidades da federação (UF). As outras tentam reforçar o

\footnotetext{
${ }^{5}$ Os trabalhos de Romero e McCombie (2016) e Marconi e Araújo (2016) reforçam a ideia de que produtos com maior valor agregado tenham maior elasticidade-renda da demanda por exportações.

${ }^{6} \mathrm{~A}$ junção de características estruturalistas com características schumpeterianas podem ser encontradas nos trabalhos de Katz (2000), Ocampo (2003) e Cimoli (2005).
} 
ponto colocado na primeira, ao utilizar proxies da demanda externa e da taxa real de câmbio. Para a demanda externa, utilizou-se o PIB dos principais parceiros comerciais de cada UF durante os anos em que foram feitas as estimações. Para a taxa de câmbio, realizou-se um ajuste da taxa real de câmbio pela paridade do poder de compra e pelos preços relativos entre setores tradeables e non-tradeables das UFs (Rodrik, 2008).

O artigo se divide em cinco seções, incluindo esta introdução. A segunda seção faz uma análise da estrutura e do contexto em que se inseriram as exportações do país e das UF nas duas últimas décadas. A terceira seção apresenta a metodologia e a fonte dos dados. $\mathrm{Na}$ quarta seção são apresentados os resultados e as discussões do trabalho. Na última seção têm-se as conclusões.

\section{ANÁLISE DA ESTRUTURA DE EXPORTAÇÕES E SEUS DETERMINANTES}

Para entender os determinantes das exportações é preciso observar uma série mais longa, que inclui alguns anos anteriores à ascensão no preço das commodities (Figura 1). A partir de 2002, o país aumentou significativamente sua quantidade exportada, de modo que, entre 2002 e 2005, a quantidade quase dobrou. Esse impulso está relacionado com a expansão do crescimento mundial, cujo Produto Interno Bruto (PIB) saltou de 33 trilhões 63 trilhões de dólares entre os anos 2001 e 2008 (World Bank, 20207). Essa elevação das exportações também foi influenciada pelo aumento no preço das commodities ${ }^{8}$, o que contribuiu para o superávit da balança comercial durante todo o período entre 2002 e 2013.

Figura 1: Balança comercial brasileira

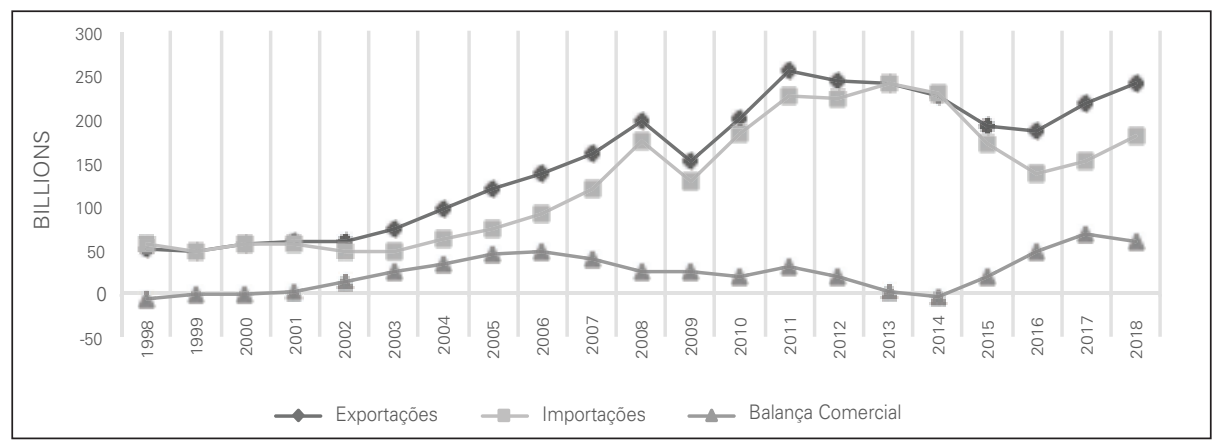

Fonte: Elaboração própria a partir de dados do sistema Comex Stat (valores em US\$ a preços correntes).

\footnotetext{
${ }^{7}$ Com base em valores correntes.

${ }^{8}$ Giambiagi et al., (2011) ressaltam que os superávits que surgiram no primeiro governo Lula devem-se, em boa parte, ao boom de preço das exportações das commodities agrícolas.
} 
Observa-se que a balança comercial começou a apresentar trajetória crescente a partir dos anos 2000. Esse crescimento está relacionado ao tripé macroeconômico implantado no final do governo Fernando Henrique Cardoso (1999), que se baseava em câmbio flutuante, superávit primário e metas de inflação. O câmbio flutuante inicialmente serviu como um estímulo para as exportações, principalmente de manufaturas, que estavam espremidas em virtude do câmbio sobrevalorizado nos anos que seguem ao Plano Real.

Em 2009, as exportações foram negativamente impactadas pelos efeitos da crise externa, mas, em 2010, já é observada uma recuperação do setor. Não apenas exportações, mas também consumo e investimento apresentam taxas positivas de crescimento em 2010 (IBGE, 2020). Isso se deve em boa parte à política anticíclica adotada no período, com aumentos na oferta de crédito por parte dos bancos privados e estatais, o que tornou a economia mais resiliente aos choques da crise externa.

Para Morais e Saad-Filho (2011), o governo brasileiro adotou medidas que estimularam a renda e a demanda, de modo que o choque externo não afetou a economia por um período. Apesar da economia voltar a crescer rapidamente, essas medidas foram questionadas por muitos economistas, principalmente os de cunho mais ortodoxo, devido ao custo fiscal que a política causou.

No entanto, o período de bonança do setor exportador durou pouco tempo, pois foi observada uma acentuada queda das exportações do país entre 2013 e 2015. O período 2011-2014 coincide com a chamada Nova Matriz Macroeconômica (NMM), política econômica do governo Dilma, que tentou conciliar câmbio desvalorizado, juros baixos e desonerações fiscais. No entanto, essa política não conseguiu atender aos seus objetivos em termos de crescimento $^{9}$, e variadas são as explicações do porquê do desempenho insatisfatório dos indicadores econômicos neste período.

Para Paula e Pires (2017), uma política fiscal anticíclica se justificava em face do baixo desempenho da economia no período da implantação da NMM, mas essa errou em privilegiar isenções fiscais ao invés de investimentos públicos e ações visando aumentar a produtividade industrial. Para Oreiro e D'Agostini (2017), o fraco desempenho da balança comercial, a partir de 2010, foi fruto da combinação de câmbio valorizado com esmagamento dos lucros (profit squeeze). Isso resultou em redução da competitividade do setor industrial brasileiro ante o mercado externo, que induziu à substituição da produção doméstica por importações. Para Marquetti et al., (2020), a queda da taxa de lucro neste período gerou descontentamento de classes que davam sustentação política ao governo ${ }^{10}$.

\footnotetext{
${ }^{9}$ Muitos fatores, tais como a crise política, escândalos de corrupção, menor crescimento da economia chinesa e até a redução da capacidade ociosa do período anterior (2000-2004) podem ter influenciado para a queda das exportações após 2011.

${ }^{10} \mathrm{O}$ fim dessa coalizão acabou sendo um dos fatores fundamentais para o impeachment da presidenta Dilma Rousseff em 2016.
} 
Diversas são as explicações sobre os fatores que influenciaram para o cenário sui generis por que passou o país após 2012. É observado que a política de crescimento com melhor distribuição de renda não é algo específico do período pós-crise. Desde 2006-2007, o aumento no consumo das famílias (IBGE, 2020), o aumento dos salários reais acima da produtividade (Serrano Summa, 2018), as políticas de aumento do salário mínimo (Carvalho Rugitsky, 2015) e a discussão sobre a ascensão de uma nova classe média (Neri, 2011) já faziam parte da realidade do país.

No entanto, essa estratégia de crescimento também influenciou para o aumento no coeficiente de importações (FIESP $\left.{ }^{11}, 2020\right)$. Em períodos de taxas altas de crescimento e de alta nos preços das commodities, essas importações não representam uma restrição ao crescimento. Mas, após o periodo de crise, é evidente que o crescimento insatisfatório em conjunto com aumento constante no coeficiente de importações foi intensificado pela falta de uma estrutura produtiva capaz de suportar uma política de crescimento voltada à demanda interna. O aumento significativo no superávit de setores não industriais e de baixa tecnologia em conjunto com déficits em setores de alta e média-alta tecnologia após 2005 (Figura 2) é um dos principais indicadores da deterioração dessa estrutura produtiva.

Figura 2: Balança comercial brasileira por nível de intensidade tecnológica

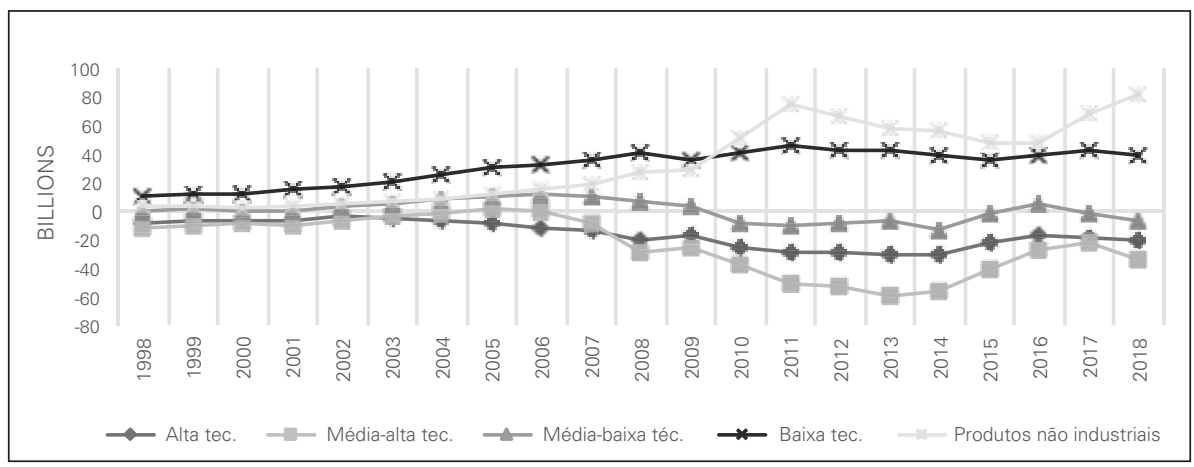

Fonte: Elaboração própria a partir de dados do sistema Comex Stat (valores em US\$ a preços correntes).

Com relação à participação relativa entre os setores (Tabela 1), também são observadas mudanças significativas. Os produtos de setores de alta e média-alta intensidade tecnológica, que representavam juntos mais de $30 \%$ do total exportado pelo país, entre 2002 e 2003, passaram para uma representatividade em torno de $20 \%$ entre 2012 e 2015 . Ao mesmo tempo, os produtos não industriais, que representavam $16 \%$ da pauta exportadora em 2001, passaram para uma representatividade de $39 \%$ em 2015 .

\footnotetext{
${ }^{11}$ Federação das Indústrias do Estado de São Paulo (FIESP).
} 
Tabela 1: Participação de cada nível de intensidade tecnológica no total exportado pelo país (1998-2018)

\begin{tabular}{ccccccc}
\hline Ano & $\begin{array}{c}\text { Alta } \\
\text { tecnologia }\end{array}$ & $\begin{array}{c}\text { Média-alta } \\
\text { tecnologia }\end{array}$ & $\begin{array}{c}\text { Média-baixa } \\
\text { tecnologia }\end{array}$ & $\begin{array}{c}\text { Baixa } \\
\text { tecnologia }\end{array}$ & $\begin{array}{c}\text { Produtos não } \\
\text { industriais }\end{array}$ & Total \\
\hline 1998 & $4.4 \%$ & $25.2 \%$ & $17.3 \%$ & $34.6 \%$ & $18.6 \%$ & $100.0 \%$ \\
1999 & $5.8 \%$ & $25.9 \%$ & $16.3 \%$ & $33.6 \%$ & $18.4 \%$ & $100.0 \%$ \\
2000 & $8.0 \%$ & $23.2 \%$ & $16.3 \%$ & $34.9 \%$ & $17.6 \%$ & $100.0 \%$ \\
2001 & $11.9 \%$ & $23.7 \%$ & $16.8 \%$ & $31.0 \%$ & $16.6 \%$ & $100.0 \%$ \\
2002 & $11.4 \%$ & $21.7 \%$ & $15.4 \%$ & $33.4 \%$ & $18.1 \%$ & $100.0 \%$ \\
2003 & $9.3 \%$ & $21.6 \%$ & $16.5 \%$ & $33.4 \%$ & $19.2 \%$ & $100.0 \%$ \\
2004 & $6.5 \%$ & $23.4 \%$ & $16.8 \%$ & $33.5 \%$ & $19.8 \%$ & $100.0 \%$ \\
2005 & $6.4 \%$ & $23.7 \%$ & $18.4 \%$ & $31.8 \%$ & $19.8 \%$ & $100.0 \%$ \\
2006 & $7.0 \%$ & $25.1 \%$ & $17.8 \%$ & $29.5 \%$ & $20.6 \%$ & $100.0 \%$ \\
2007 & $6.4 \%$ & $24.6 \%$ & $18.6 \%$ & $28.2 \%$ & $22.3 \%$ & $100.0 \%$ \\
2008 & $6.0 \%$ & $23.6 \%$ & $18.2 \%$ & $27.9 \%$ & $24.3 \%$ & $100.0 \%$ \\
2009 & $5.4 \%$ & $21.1 \%$ & $18.0 \%$ & $26.4 \%$ & $29.1 \%$ & $100.0 \%$ \\
2010 & $5.5 \%$ & $18.6 \%$ & $14.7 \%$ & $30.1 \%$ & $31.0 \%$ & $100.0 \%$ \\
2011 & $4.2 \%$ & $18.9 \%$ & $12.7 \%$ & $27.6 \%$ & $36.6 \%$ & $100.0 \%$ \\
2012 & $3.3 \%$ & $17.7 \%$ & $13.3 \%$ & $25.0 \%$ & $40.8 \%$ & $100.0 \%$ \\
2013 & $3.8 \%$ & $17.6 \%$ & $14.2 \%$ & $25.5 \%$ & $38.9 \%$ & $100.0 \%$ \\
2014 & $3.7 \%$ & $17.2 \%$ & $15.4 \%$ & $25.7 \%$ & $38.0 \%$ & $100.0 \%$ \\
2015 & $4.0 \%$ & $16.3 \%$ & $13.7 \%$ & $26.7 \%$ & $39.3 \%$ & $100.0 \%$ \\
2016 & $4.8 \%$ & $17.3 \%$ & $14.2 \%$ & $27.9 \%$ & $35.7 \%$ & $100.0 \%$ \\
2017 & $5.3 \%$ & $18.1 \%$ & $14.6 \%$ & $29.2 \%$ & $32.8 \%$ & $100.0 \%$ \\
2018 & $4.6 \%$ & $18.5 \%$ & $12.8 \%$ & $26.5 \%$ & $37.6 \%$ & $100.0 \%$ \\
\hline
\end{tabular}

Fonte: Elaboração própria, com base nos dados do Comex Stat.

Ao considerar uma análise mais regional das exportações (Figura 3, em apêndice $^{12}$ ), um dos pontos que se tenta dar atenção no artigo, observa-se que os estados do Amazonas, de Santa Catarina e de São Paulo apresentaram desvio-padrão acima da média nas exportações de alta tecnologia. Os estados das Regiões Sul e Sudeste, e o estado da Bahia se destacam em média-alta tecnologia. Os produtos de menor intensidade tecnológica apresentaram uma distribuição mais igual, com vários estados com níveis de exportação acima ou próximo da média nacional. No que tange ao PIB, pode ser observado que existe uma relação positiva entre estados que apresentam alta renda per capita e estados que são potenciais exportadores ${ }^{13}$. Entre outros fatores, a Figura 3, em apêndice, mostra a heterogeneidade da

\footnotetext{
${ }^{12}$ A análise está em desvio-padrão, o que permite verificar a dispersão de determinado estado em relação à média nacional.

13 O Distrito Federal foi o único que apresentou mais de quatro desvios-padrão em relação à média, mas acredita-se que essa renda elevada está mais relacionada com outras questões, como a função administrativa que essa UF exerce, e não, propriamente, com sua estrutura de exportações.
} 
estrutura produtiva e da renda dentro do território nacional e ressalta a importância de considerar essas especificidades nas estimações econométricas.

\section{METODOLOGIA}

A estimação por métodos de momentos generalizados (GMM), inicialmente desenvolvidos por Holtz-Eakin, Newey e Rosen (1988) e, posteriormente, por Arellano e Bond (1991), Arellano e Bover (1995), e Blundell e Bond (1998), tem sido bastante utilizada na literatura empírica para casos em que as variáveis não são estritamente exógenas.

Para Roodman (2009), os estimadores de painéis dinâmicos são indicados para situações em que: i) as variáveis não são estritamente exógenas, ou seja, são correlacionadas com seus valores passados e possivelmente com os erros presentes; ii) a variável dependente apresenta tendência temporal, dependendo de seus valores nos períodos anteriores; iii) existe um grande número de indivíduos no painel; iv) existe heteroscedasticidade e autocorrelação dentro dos indivíduos, mas não entre eles. Nos testes de especificação, os dados do presente trabalho apresentaram várias das características citadas por Roodman (2009), o que levou à utilização de painéis dinâmicos ${ }^{14}$ System GMM a fim de eliminar o viés nas estimativas. Maiores detalhes teóricos sobre a abordagem de painéis dinâmicos podem ser vistos em apêndice.

Neste contexto, ao considerar um modelo dinâmico simples, a especificação das estimações deste artigo ${ }^{15}$ pode ser apresentada da seguinte forma:

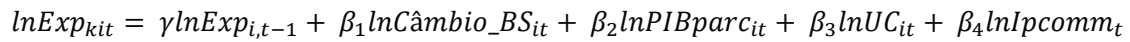

$$
\begin{aligned}
& +\beta_{5} \operatorname{lnFBCF}_{t}+\beta_{6} \text { lnJuros }_{t}+\alpha_{k i}+\varepsilon_{\text {kit }}
\end{aligned}
$$

em que $\ln$ representa o logaritmo natural ${ }^{16}, \mathrm{i}=1, \ldots, \mathrm{n}$ corresponde aos estados do Brasil, incluindo o Distrito Federal, $\mathrm{t}=1, \ldots, \mathrm{T}$ corresponde aos anos da amostra, que vão de 2003 até 2014, $\alpha_{k i}$ é o efeito não observado específico de cada unidade federativa e $\varepsilon_{k i t}$ é o termo de erro. Os parâmetros do modelo são representados por $\gamma$ e pelos $\beta^{\prime}$ s. A variável dependente é representada pelas exportações, sendo que $k$ corresponde à divisão por intensidade tecnológica dessas exportações (totais, alta tecnologia, média-alta tecnologia, média-baixa tecnologia, baixa tecnologia e produtos não industriais).

A variável Câmbio_BS é a taxa real de câmbio ajustada pelo efeito Balassa-

\footnotetext{
${ }^{14}$ Foi estimado painel dinâmico em dois estágios. Cameron e Trivedi (2005, p. 756) consideram que a estimação em dois estágios é mais eficiente e tende a apresentar menores erros-padrões do que a estimação em um estágio.

${ }^{15} \mathrm{O}$ software utilizado para a estimação das equações foi o Stata 14.

${ }^{16}$ Foi utilizada a versão log-log para permitir que os $\beta^{\prime} S$ sejam interpretados como elasticidades.
} 
Samuelson para as UF ${ }^{17}$. PIBparc representa o PIB dos principais parceiros comerciais de cada UF entre os anos que foram feitas as estimações. Ipcomm representa o índice de preço das commodities, FBCF é a formação bruta de capital fixo, utilizada como proxy do investimento. UC é o grau de utilização da capacidade estadual, cuja proxy é o consumo intermediário da indústria de transformação. Juros é a taxa real de juros do período.

\section{Fonte de dados}

No presente artigo, foram utilizadas as seguintes séries de dados:

- Exportações estaduais totais e por níveis de intensidade tecnológica-Comex Stat/SECEX ${ }^{18}$.

- Taxa efetiva real de câmbio para exportações de manufaturas - coletada no site do Instituto de Pesquisa Econômica Aplicada (IPEA). Essa metodologia utiliza a média aritmética ponderada das taxas de câmbio reais bilaterais do país em relação a 23 parceiros comerciais selecionados.

- PIB dos principais destinos das exportações de cada UF - Penn World Table (PWT). Foram utilizados no mínimo cinco e no máximo dez principais parceiros comerciais para cada UF ${ }^{19}$.

- Grau de utilização da capacidade, cuja proxy é o consumo intermediário da indústria de transformação - Instituto Brasileiro de Geografia e Estatística (IBGE).

- Taxa real de juros, cuja proxy é a taxa Selic, descontada pela inflação dos últimos 12 meses - Banco Central do Brasil.

- Índice de preço das commodities - Fundo Monetário Internacional (FMI).

- Formação Bruta de Capital Fixo, como proxy para investimento - IPEA.

- PIB per capita das UF - IPEA.

- Preço e tempo de trabalho necessário para a compra de um conjunto de produtos alimentícios considerados essenciais (cesta básica de alimentos) nas capitais do país - Departamento Intersindical de Estatística e Estudos Socioeconômicos (DIEESE).

As variáveis foram escolhidas com base na literatura que trata dos determinantes das exportações, bem como em fatores que ocorreram no período em que foram realizadas as estimações. A priori, com base em trabalhos já realizados e na li-

\footnotetext{
${ }^{17}$ Maiores detalhes em apêndice.

18 Sistema de análise das informações de comércio exterior.

${ }^{19}$ Para algumas UFs, o PIB de apenas cinco parceiros comerciais foi suficiente, pois já representavam quase a totalidade da demanda por suas exportações.
} 
teratura sobre e tema, foram esperados efeitos positivos da taxa real de câmbio, da demanda externa e do índice de preço das commodities, e negativos da utilização da capacidade e da taxa de juros. No entanto, a literatura que diferencia as exportações por grau tecnológico e por unidades da federação ainda é escassa, sendo difícil a análise do efeito esperado de algumas variáveis.

\section{ANÁLISE E DISCUSSÃO DOS RESULTADOS}

As Tabelas 2 a 7, em apêndice, apresentam os resultados das estimações dos modelos de dados em painel para os estados do Brasil. As variáveis dependentes para cada tabela são o total exportado e as exportações de cada nível de intensidade tecnológica ${ }^{20}$ (alta, média-alta, média-baixa, baixa e não industriais), respectivamente. As estimações por painel dinâmico deveram-se ao fato de algumas variáveis (taxa de câmbio e utilização da capacidade) apresentarem algum grau de endogeneidade, testado através do teste de endogeneidade de Hausman ${ }^{21}$. A FBCF é uma variável de controle, a demanda externa é exógena por natureza e o preço das commodities também é tomado como exógeno, pois a participação do Brasil no mercado mundial é pequena, o que exclui a possibilidade de o país ser um formador de preços.

De início, é importante destacar que somente foram analisados os resultados com significância estatística. Todos os setores de exportações apresentaram tendência temporal, com coeficientes defasados positivos e abaixo da unidade, o que respeita as condições de estabilidade do modelo dinâmico.

Ao considerar o total exportado como variável dependente, observa-se que a taxa real de câmbio apresentou correlação negativa no período contemporâneo e positiva, com valores acima da unidade, na defasagem ${ }^{22}$. Isso indica que um aumento (depreciação) da taxa de câmbio tende a apresentar relação positiva com o total exportado em ano posterior.

A mudança na trajetória dos coeficientes que representa o câmbio, ou seja, de um coeficiente negativo no período contemporâneo para positivo na defasagem, é conhecida na literatura como curva J. Isso porque a depreciação tende a aumentar o custo relativo dos produtos importados. Ao considerar que parte da exportação de bens finais depende de insumos intermediários importados, em um primeiro momento, o efeito da depreciação cambial sobre as exportações tende a ser negativo. Observaram-se também efeitos positivos da demanda externa e do preço das commodities sobre o total exportado. Isso já era esperado, pois o setor exportador no

\footnotetext{
${ }^{20}$ Nakabashi et al., (2008) fez uma análise parecida utilizando séries de tempo.

${ }^{21}$ A abordagem System GMM é útil para este caso, pois permite que se trate as variáveis como exógenas, endógenas ou predeterminadas.

22 O trabalho de Sonaglio et al., (2010) também apresentou esses resultados para a variável taxa real de câmbio.
} 
Brasil, principalmente não industrial, foi beneficiado pelo cenário externo favorável de aumento na renda externa e nos preços de commodities.

A proxy de utilização da capacidade (UC) apresentou efeitos positivos sobre as exportações totais no período contemporâneo e negativos em t-1. Esse efeito negativo em t-1 pode ocorrer quando o crescimento da economia está mais voltado para atender mais a demanda interna do que a demanda externa (exportações). Como foi utilizado o consumo intermediário da indústria como proxy para o nível de utilização da capacidade, períodos seguidos de maior utilização de bens intermediários no mercado interno podem reduzir a oferta desses insumos que serve para atender as exportações. Sonaglio et al., (2010) também observaram que as exportações respondem negativamente para os lags da utilização da capacidade. Em uma linha similar, Esteves e Rua (2013) verificaram, para o caso da economia portuguesa, que o lag da demanda doméstica afeta negativamente a performance das exportações. Ademais, a proxy para investimento apresentou efeitos negativos e a taxa de juros apresentou efeitos positivos sobre o total exportado, o que não era esperado.

Passando para a análise dos setores de intensidade tecnológica (Tabelas 3-7), observa-se que os resultados não apresentaram muitas diferenças se comparados com as exportações totais (Tabela 2). No entanto, a desagregação das exportações permite explorar melhor alguns fatores isolados nas estimações. Os setores de alta e baixa intensidade tecnológica apresentaram pouca significância estatística, o que impede de analisá-los em maiores detalhes. Acredita-se que essa falta de significância para o setor de alta tecnologia foi influenciada pela inexistência de exportações desse setor em algumas UFs para alguns anos da análise. Isso reforça a análise da segunda seção, em que foram destacadas as diferenças existentes na estrutura de exportações dentro do território nacional.

Foram encontrados coeficientes significativos da utilização da capacidade nas exportações de média-baixa tecnologia. Tal como para as exportações totais, a correlação foi positiva no período contemporâneo e negativa na defasagem. A demanda externa se mostrou positivamente correlacionada com todos os setores, mas com maiores elasticidades sobre os produtos não industriais e de média-alta intensidade tecnológica. O primeiro caso é explicado em virtude de a base de dados do artigo abranger todo o período considerado como boom das commodities, em grande parte proporcionado pelo bom desempenho da economia chinesa no período. A China se destacou a partir dos anos 2000 como uma potência econômica, tornando-se o principal destino das exportações do Brasil, principalmente no que tange a produtos primários. Isso também foi um estimulante para o ganho participativo dos produtos não industriais na pauta de exportações.

Apesar de parecer contraditório, o próprio cenário positivo do período de alta no preço das commodities explica a alta elasticidade da renda externa sobre a exportação de produtos de média-alta tecnologia. Isso porque todos os países exportadores líquidos de commodities, realidade das economias da América do Sul (Sinnott et al., 2010), beneficiaram-se no período. Dessa forma, as exportações bra- 
sileiras de média-alta tecnologia também foram beneficiadas pelo efeito renda dos países vizinhos. Exemplos disso foi o aumento considerável das exportações da indústria automobilista para a Argentina e para a Venezuela, a partir de 2004 (Comtrade, 2020).

Na mesma linha, destaca-se a dinâmica da taxa de câmbio como um mecanismo facilitador da capacidade de acesso aos mercados internacionais de parte importante dos setores produtivos domésticos. A taxa real de câmbio apresentou coeficientes positivos justamente sobre o setor de média-alta intensidade tecnológica. A correlação foi negativa no período contemporâneo em virtude da demora na capacidade de ajuste, mas positivo e com alta elasticidade na defasagem. Isso indica que períodos em que a taxa de câmbio se depreciava eram seguidos por aumentos significativos das exportações de média-alta tecnologia, provavelmente produtos relacionados à indústria automobilística.

Esses resultados vão ao encontro da abordagem novo-desenvolvimentista de Bresser-Pereira, Oreiro e Marconi (2016) e da abordagem multissetorial da lei de Thirlwall (1979). Os primeiros defendem que uma taxa de câmbio desvalorizada pode influenciar no aumento das exportações de setores de tecnologia mais avançada, pois esses setores normalmente não apresentam vantagens comparativas, necessitando concorrer via preço no mercado internacional. A versão multissetorial da lei de Thirlwall (Araújo Lima, 2007), por sua vez, considera que uma alteração na composição da pauta de comércio permite a determinado país alcançar maiores taxas de crescimento, sem depender diretamente da taxa de crescimento mundial. O principal meio de isso ocorrer é pelo aumento da participação nas exportações de produtos com maior elasticidade-renda da demanda.

\section{CONCLUSÕES}

A partir dos dados e das estimações realizadas no trabalho, podem ser feitas algumas considerações. $\mathrm{Na}$ análise dos dados, foi observado que as exportações do Brasil são pouco diversificadas e, especificamente após o ano de 2005, passaram a perder representatividade em setores de alta e média-alta intensidade tecnológica. Também foi observado que as exportações de maior tecnologia são bastante concentradas no eixo Sul-Sudeste. As estimações indicaram que as exportações totais são positivamente correlacionadas com a renda externa, com o preço das commodities e com a defasagem da taxa real de câmbio.

Ao desagregar as exportações em setores, foi possível observar algumas características que ajudam a explicar o cenário por que passou a economia brasileira entre 2003 e 2014. Verificou-se que o efeito renda (renda externa) foi um dos principais determinantes das exportações de produtos não industriais e de média-alta intensidade tecnológica. Apesar de contraditório, considera-se que o efeito renda em ambos os setores está relacionado com a ascensão no índice de preço das com- 
modities. Esse efeito renda pode ser dividido em primário e secundário. As exportações de produtos não industriais foram impactadas pelo efeito renda primário, decorrência direta da maior renda da economia chinesa e, por sua vez, da maior demanda por produtos agrícolas e minerais. Para os produtos de média-alta tecnologia, considera-se o efeito renda secundário e decorrente dos demais países da América Latina. Isso porque esses países também são exportadores líquidos de commodities e se beneficiaram, em termos de renda, com a dinâmica de maior crescimento da China. Essa situação, entre outros fatores, explica o aumento significativo das exportações da indústria automobilística para a Argentina e para a Venezuela a partir de 2004.

$\mathrm{Na}$ mesma linha, verificou-se que a taxa real de câmbio funcionou como um facilitador de acesso ao mercado internacional de setores exportadores de média-alta intensidade tecnológica, que engloba os produtos da indústria automobilísti$\mathrm{ca}$, entre outros $\left(\mathrm{NCM}^{23}, 2020\right)$. No entanto, a resposta positiva do setor de média-alta tecnologia com relação à taxa de câmbio não ocorre de maneira direta. $\mathrm{O}$ efeito inicial pode ser negativo, mas se torna positivo no decorrer do tempo. Isso demonstra que políticas cambiais devem ser pensadas em médio e longo prazo e que variações repentinas da taxa de câmbio, muitas vezes em virtude de maior instabilidade interna, não surtem efeitos positivos diretos na estrutura produtiva. Variações repentinas nas taxas de câmbio têm efeitos reduzidos sobre as expectativas dos agentes econômicos sobre a taxa de câmbio no futuro.

Dessa forma, conclui-se que a análise dos determinantes das exportações setoriais ajuda a explicar o cenário por que passou a economia brasileira no período de ascensão no preço das commodities. De uma maneira geral, considerou-se que essa ascensão no preço das mercadorias exportadas colocou a economia brasileira em uma dinâmica positiva após 2003. Ao mesmo tempo, isso também indica maior vulnerabilidade com relação aos ciclos desses preços. Por isso, ressalta-se a importância de ser mais competitivo em manufaturas e o papel da taxa de câmbio neste processo. Os mecanismos do câmbio e seus efeitos sobre a diversificação da estrutura produtiva são pouco discutidos em períodos de bonança, principalmente quando a elevação no coeficiente de importações é sustentada por taxas positivas de crescimento e maiores exportações. No entanto, os efeitos negativos de uma taxa de câmbio sobrevalorizada em longo prazo se tornam evidentes. Principalmente quando a economia aumenta seus padrões de consumo e/ou adota políticas anticíclicas de incentivo à demanda interna, e a indústria não é capaz de atender a essa demanda, causando aumento do coeficiente de importações, maior restrição externa e, por sua vez, efeitos reduzidos da estratégia de crescimento com consumo das massas sobre a real atividade econômica.

Por fim, o ponto positivo é saber que o Brasil continua abundante em recursos

\footnotetext{
${ }^{23}$ Nomenclatura Comum do Mercosul.
} 
naturais e que a economia chinesa continua em ascensão. Isso ainda pode ter efeitos reais sobre o preço das commodities por um período considerável, o que poderia colocar o país novamente em uma trajetória ascendente de crescimento. No entanto, é preciso aprender com o passado para não errar novamente no futuro.

\section{REFERÊNCIAS BIBLIOGRÁFICAS}

ANDERSON, T. W.; HSIAO, C. (1981) Estimation of dynamic models with error components. Journal of the American Statistical Association, v. 76, n. 375, p. 598-606.

ARAUJO, R. A.; LIMA, G. T. A. (2007) structural economic dynamics approach to balance-of-payments-constrained growth. Cambridge Journal of Economics, v. 31, n. 5, p. 755-774, 2007.

ARELLANO, M; BOND, S. (1991) "Some tests of specification for panel data: Monte Carlo evidence and an application to employment equations". The Review of Economic Studies, v. 58, n. 2, p. 277-297.

BHADURI, A; MARGLIN, S. (1990) Unemployment and the real wage: the economic basis for contesting political ideologies. Cambridge Journal of Economics, v. 14, n. 4, p. 375-393, 1990.

BLECKER, R. A. (2002) Distribution, demand and growth in neo-Kaleckian macro-models. In: Setterfield, M. The Economics of Demand-Led Growth. Edward Elgar Publishing, 2002.

BRESSER-PEREIRA, L. C. (2007) Novo desenvolvimentismo e ortodoxia convencional. In: Globalização, Estado e desenvolvimento: dilemas do Brasil no novo milênio, v. 20, n. 3, p. 63-96.

BRESSER-PEREIRA, L. C.; OREIRO, J. L.; MARCONI, N. (2016) Macroeconomia Desenvolvimentis$t a$. Rio de Janeiro: Elsevier.

BLUNDELL, R; BOND, S. (1998) Initial conditions and moment restrictions in dynamic panel data models. Journal of econometrics, v. 87, n. 1, p. 115-143.

CAMERON, A. C.; TRIVEDI, P. K. (2005) “Microeconometrics: methods and applications”. Cambridge University Press.

CARNEIRO, R. M. (2012) “Commodities, choques externos e crescimento: reflexões sobre a América Latina”. CEPAL. Série: Macroeconomia del desarrollo, n. 117.

CIMOLI, M. (2005) Heterogeneidad estructural, asimetrias tecnologicas y crecimiento en America Latina. Comisión Económica para América Latina y el Caribe (CEPAL). Santiago de Chile.

CARVALHO, L.; RUGITSKY, F. (2015) "Growth and distribution in Brazil the 21st century: revisiting the wage-led versus profit-led debate”. [s.l.] University of São Paulo.

DIXON, R.; THIRLWALL A. P. (1975) "A Model of Regional Growth-Rate Differences on Kaldorian Lines”. Oxford Economic Papers, New Series, Vol. 27, No. 2. pp. 201-214.

DUGGER, W. M.; SHERMAN, H. J. (2000) Reclaiming evolution: A dialogue between Marxism and institutionalism on social change. Psychology Press.

ESTEVES, P. S.; RUA, A. (2015) Is there a role for domestic demand pressure on export performance?. Empirical Economics, v. 49, n. 4, p. 1173-1189.

FURTADO, C. (1971) Teoria e política do desenvolvimento econômico. [S.l: s.n.].

GIAMBIAGI, F.; VILLELA, A.; LAVINIA, B, C.; JENNIFER, H. (2011) Economia Brasileira Contemporânea: 1945-2010. 2. Ed. Rio de Janeiro: Campus Elsevier.

HIDALGO, C. (2015) Why Information Grows: the evolution of order, from atoms to economics. New York: Basic Books.

KALDOR, N. (1957) “A model of economic growth”. Economic Journal, v. 67, n. 268, p. 591-624.

KATZ, J. (2000) Reformas estructurales, productividad y conducta tecnologica en America Latina. Comisión Económica para América Latina y el Caribe (CEPAL). Santiago de Chile.

KRUGMAN, P. R. (1991) Geography and trade. MIT press. 
LIBÂNIO, G; MORO, S; LONDE, A. C. (2014) "Qualidade das exportações e crescimento econômico nos anos 2000". Anais do 42 . Encontro Nacional de Economia-ANPEC. Natal/RN.

MARCONI, N; ARAÚJO, E. C. (2016) "Estrutura produtiva e comércio exterior no Brasil: uma investigação sobre as elasticidades-renda da demanda por exportações e importações setoriais”. Brazilian Keynesian Review, v. 2, n. 1, p. 40-59.

MARQUETTI, A. A.; HOFF, C.; MIEBACH, A. (2020) "Profitability and Distribution: The Origin of the Brazilian Economic and Political Crisis". Latin American Perspectives, v. 47, n. 1, p. 115-133.

MORAIS, L; SAAD-FILHO, A. (2011) "Da economia política à política econômica: o novo-desenvolvimentismo e o governo Lula”. Revista de Economia Política, v. 31, n. 4, p. 507-527.

NAKABASHI, L; CRUZ, M. J. V; SCATOLIN, F. D. (2008) "Efeitos do câmbio e juros sobre as exportações da indústria brasileira”. Revista de Economia Contemporânea, v. 12, n. 3, p. 433-461.

NERI, M. C. (2011) A nova classe média: o lado brilhante da base da pirâmide. São Paulo: Editora Saraiva.

OCAMPO, J. A. (2003) Lights and shadows in Latin American structural reforms. In: Economic refor$m s$, growth and inequality in Latin America: Essays in honor of Albert Berry.

OREIRO, J. L.; D'AGOSTINI, L. (2017) “Macroeconomic policy regimes, real exchange rate overvaluation, and performance of the Brazilian economy (2003-2015)". Journal of Post Keynesian Economics, V. 40, N. 1, p. 1-16.

PAULA, L. F.; PIRES, M. (2017) “Crise e perspectivas para a economia brasileira”. Estudos Avançados, v. 31, n. 89, p. 125-144.

PRATES, D. M. (2007) A alta recente dos preços das commodities. Revista de Economia Política, vol. 27, no 3 (107), pp. 323-344, julho-setembro.

PREBISCH, R. (1949) O desenvolvimento econômico da América Latina e seus principais problemas. Revista Brasileira de Economia, v. 3, n. 3, p. 47-111.

RODRIK, D. (2008) The real exchange rate and economic growth. Brookings papers on economic activity, v. 2008, n. 2, p. 365-412.

ROMERO, J. P.; MCCOMBIE, J. SL. (2016) “The Multi-Sectoral Thirlwall's Law: evidence from 14 developed European countries using product-level data". International Review of Applied Economics, v. 30, n. 3, p. 301-325.

RODRIGUEZ, O. (2009) O Estruturalismo Latino-Americano. Rio de Janeiro: Civilização Brasileira.

SERRANO, F. (2014) A mudança na tendência dos preços das commodities nos anos 2000: aspectos estruturais. Revista OIKOS, Rio de Janeiro, v. 12, n. 2.

SERRANO, F.; SUMMA, R. (2018). "Conflito Distributivo e o Fim da "Breve Era de Ouro" da Economia Brasileira”. Novos estudos CEBRAP, v. 37, n. 2, p. 175-189.

SINNOTT, E; NASHAT, B; DE LA TORRE, A. (2010) Natural resources in Latin America and the Caribbean: beyond booms and busts?. The World Bank, Washington.

SONAGLIO, C. M.; ZAMBERLAN, C. O., LIMA, J. E.; CAMPOS, A. C. (2010) "Evidências de desindustrialização no Brasil: uma análise com dados em painel”. Economia Aplicada, v. 14, n. 4, p. 347-372.

SUNKEL, O. (1958) La inflación chilena: un enfoque heterodoxo. El trimestre económico, v. 25, n. 4, p. 570-599.

THIRLWALL, A. P. (1979) “The balance of payments constraint as an explanation of the international growth rate differences". PSL Quarterly Review, v. 32, n. 128. 
Figura 3: Exportações por níveis de intensidade tecnológica e o PIB per capita das unidades federativas (1998-2014)

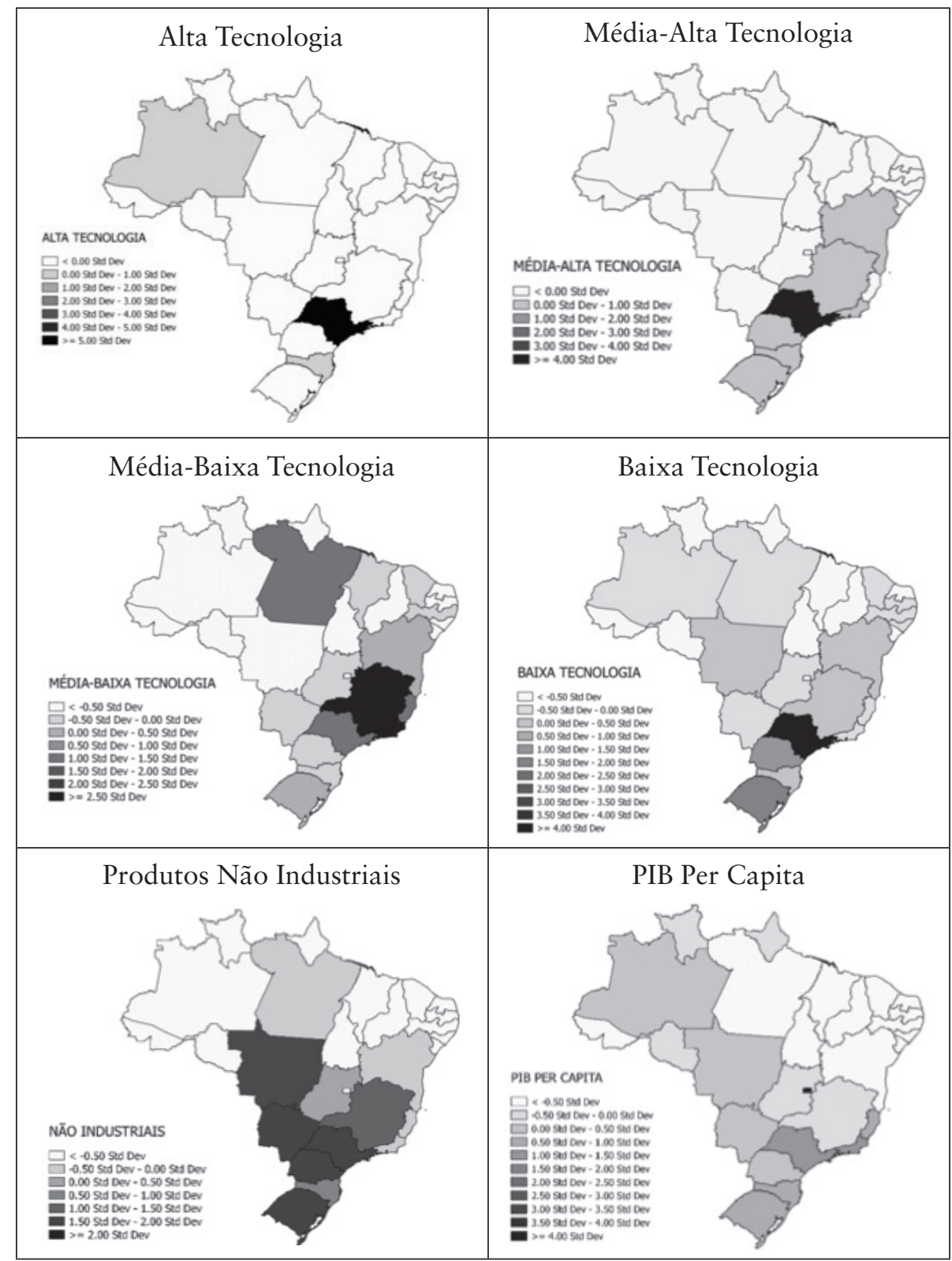

Nota: Diferença por Desvio-Padrão.

Fonte: Elaboração própria com dados do sistema Comex Stat e IPEADATA, com base no software QGI. 
Tabela 2: System GMM (Variável Dependente: Total Exportado (In))

\begin{tabular}{|c|c|c|c|c|c|c|}
\hline Variáveis & (1) & (2) & (3) & (4) & (5) & (6) \\
\hline \multirow[t]{2}{*}{ Ln Total (t-1) } & $0.679 * * *$ & 0.324 & $0.525^{*}$ & $1.020 * * *$ & $0.929 * * *$ & $0.808 * * *$ \\
\hline & $(0.107)$ & $(0.257)$ & $(0.281)$ & (0.185) & $(0.137)$ & $(0.260)$ \\
\hline \multirow[t]{2}{*}{ Ln Câmbio_BS } & $-1.366 * * *$ & $-0.945^{* *}$ & -0.815 & $-1.051^{*}$ & -0.432 & 0.368 \\
\hline & $(0.468)$ & $(0.388)$ & $(0.520)$ & (0.555) & (0.510) & $(0.672)$ \\
\hline \multirow[t]{2}{*}{ Ln Câmbio_BS (t-1) } & 0.379 & 0.831 & $1.165^{* *}$ & $2.053 * * *$ & $1.598 * * *$ & 0.0255 \\
\hline & $(0.520)$ & $(0.656)$ & (0.583) & $(0.546)$ & $(0.416)$ & (0.895) \\
\hline \multirow[t]{2}{*}{ Ln PIBparc } & & $1.841 * *$ & 1.308 & 0.408 & $0.527^{*}$ & 0.634 \\
\hline & & $(0.773)$ & (0.989) & $(0.342)$ & (0.303) & $(0.459)$ \\
\hline \multirow[t]{2}{*}{ Ln Ipcomm } & & & 0.289 & $0.943 * *$ & $1.696 * * *$ & $2.657 * * *$ \\
\hline & & & (0.638) & (0.395) & $(0.450)$ & (0.665) \\
\hline \multirow[t]{2}{*}{$\operatorname{Ln} \cup C$} & & & & $1.153^{*}$ & $1.241 * *$ & $1.570 * * *$ \\
\hline & & & & (0.609) & (0.543) & $(0.471)$ \\
\hline \multirow[t]{2}{*}{$\operatorname{Ln} \cup C(t-1)$} & & & & $-1.369 * *$ & $-1.408^{* *}$ & $-1.643 * * *$ \\
\hline & & & & (0.615) & $(0.571)$ & (0.513) \\
\hline \multirow[t]{2}{*}{ Ln FBCF } & & & & & $-0.883^{*}$ & $-2.216^{* *}$ \\
\hline & & & & & (0.458) & $(0.866)$ \\
\hline \multirow[t]{2}{*}{ Ln Juros } & & & & & & $0.333^{* *}$ \\
\hline & & & & & & $(0.145)$ \\
\hline \multirow[t]{2}{*}{ Constante } & $11.24 * * *$ & -13.41 & $-12.86^{* *}$ & $-13.20 * * *$ & $-13.22 * * *$ & $-7.804^{* *}$ \\
\hline & (3.078) & (11.36) & (6.346) & (4.331) & (3.346) & (3.606) \\
\hline $\begin{array}{l}\text { Número de } \\
\text { instrumentos }\end{array}$ & 11 & 23 & 24 & 29 & 30 & 31 \\
\hline AR (2) & 0,976 & 0,510 & 0,484 & 0,882 & 0,920 & 0,793 \\
\hline Teste de Hansen & 0,018 & 0,101 & 0,098 & 0,235 & 0,284 & 0,319 \\
\hline $\begin{array}{l}\text { Lag dos } \\
\text { instrumentos }\end{array}$ & 2 & 2 & 2 & 4 & 4 & 4 \\
\hline
\end{tabular}

Fonte: Elaboração própria.

Nota 1: Erros-padrão entre parênteses. ${ }^{* *} p<0.01,{ }^{*} p<0.05,{ }^{*} p<0.1$.

Nota 2: Foi utilizada a correção para erros-padrão proposta por Windmeijer (2005).

Tabela 3: System GMM (Variável Dependente: Alta Tecnologia (In))

\begin{tabular}{lcccccc}
\hline \multicolumn{1}{c}{ Variáveis } & $(1)$ & $(2)$ & $(3)$ & $(4)$ & $(5)$ & $(6)$ \\
\hline Ln Alta Tec (t-1) & $0.811^{* * *}$ & 0.228 & $0.357^{* * *}$ & 0.0186 & 0.0751 & 0.00860 \\
& $(0.207)$ & $(0.217)$ & $(0.123)$ & $(0.159)$ & $(0.148)$ & $(0.147)$ \\
Ln Câmbio_BS & -0.114 & -0.747 & -1.330 & -4.116 & -1.591 & 2.700 \\
& $(1.372)$ & $(1.637)$ & $(1.735)$ & $(3.274)$ & $(3.476)$ & $(2.809)$ \\
Ln Câmbio_BS (t-1) & -0.394 & 0.617 & -1.557 & -0.300 & -1.784 & $-8.372^{* *}$ \\
& $(1.346)$ & $(1.921)$ & $(1.692)$ & $(2.755)$ & $(1.998)$ & $(4.193)$ \\
Ln PIBparc & & 2.289 & 1.793 & -2.412 & -1.558 & -1.971 \\
\hline
\end{tabular}




\begin{tabular}{|c|c|c|c|c|c|c|}
\hline & & $(1.580)$ & $(1.223)$ & (3.376) & (3.228) & $(2.742)$ \\
\hline \multirow[t]{2}{*}{ Ln Ipcomm } & & & -2.151 & $-4.590 * *$ & -2.702 & 2.680 \\
\hline & & & $(1.606)$ & $(2.096)$ & $(4.656)$ & (3.683) \\
\hline \multirow[t]{2}{*}{$\operatorname{Ln} \cup C$} & & & & -6.171 & -3.657 & -0.856 \\
\hline & & & & $(5.930)$ & (5.373) & $(5.324)$ \\
\hline \multirow[t]{2}{*}{$\operatorname{Ln} \cup C(t-1)$} & & & & 8.889 & 5.987 & 3.503 \\
\hline & & & & (5.819) & (5.206) & (5.123) \\
\hline \multirow[t]{2}{*}{ Ln FBCF } & & & & & -1.677 & -7.311 \\
\hline & & & & & $(4.310)$ & $(4.570)$ \\
\hline \multirow[t]{2}{*}{ Ln Juros } & & & & & & $1.595^{*}$ \\
\hline & & & & & & $(0.900)$ \\
\hline \multirow[t]{2}{*}{ Constante } & 5.128 & -23.59 & 4.710 & 62.87 & 48.41 & 65.00 \\
\hline & (6.175) & (28.24) & (15.71) & (39.06) & (35.36) & (43.37) \\
\hline $\begin{array}{l}\text { Número de } \\
\text { instrumentos }\end{array}$ & 23 & 21 & 24 & 29 & 30 & 31 \\
\hline$A R(2)$ & 0,292 & 0,441 & 0,262 & 0,686 & 0,562 & 0,738 \\
\hline Teste de Hansen & 0,311 & 0,268 & 0,637 & 0,244 & 0,393 & 0,577 \\
\hline Lag dos instrumentos & 3 & 3 & 2 & 4 & 4 & 4 \\
\hline
\end{tabular}

Fonte: Elaboração própria.

Nota 1: Erros-padrão entre parênteses. ${ }^{* *} p<0.01,{ }^{*} p<0.05,{ }^{*} p<0.1$.

Nota 2: Foi utilizada a correção para erros-padrão proposta por Windmeijer (2005).

Tabela 4: System GMM (Variável Dependente: Média-alta Tecnologia (In))

\begin{tabular}{|c|c|c|c|c|c|c|}
\hline Variáveis & (1) & (2) & (3) & (4) & (5) & (6) \\
\hline \multirow[t]{2}{*}{ Ln Mealta Tec (t-1) } & $0.650 * * *$ & $0.463^{* * *}$ & $0.413^{* *}$ & 0.365 & 0.267 & 0.274 \\
\hline & $(0.250)$ & $(0.170)$ & (0.169) & $(0.242)$ & $(0.256)$ & $(0.270)$ \\
\hline \multirow[t]{2}{*}{ Ln Câmbio_BS } & $-1.948^{*}$ & $-1.830 * *$ & $-2.195 * *$ & -2.905 & -0.425 & -1.439 \\
\hline & (1.088) & (0.904) & $(0.890)$ & $(2.481)$ & $(2.292)$ & $(2.531)$ \\
\hline \multirow[t]{2}{*}{ Ln Câmbio_BS (t-1) } & $1.256^{* *}$ & $2.503 * * *$ & $2.076 * * *$ & $1.980 * *$ & 0.984 & 1.687 \\
\hline & $(0.600)$ & (0.688) & (0.749) & $(0.827)$ & $(0.767)$ & $(2.424)$ \\
\hline \multirow[t]{2}{*}{ Ln PIBparc } & & $2.719 * * *$ & $2.951 * *$ & 0.634 & 1.105 & 1.290 \\
\hline & & (1.010) & (1.213) & $(1.008)$ & $(1.248)$ & $(1.362)$ \\
\hline \multirow[t]{2}{*}{ Ln Ipcomm } & & & -0.648 & -1.273 & 2.669 & 1.757 \\
\hline & & & (0.965) & (1.658) & (1.905) & $(2.281)$ \\
\hline \multirow[t]{2}{*}{ Ln UC } & & & & $4.198^{*}$ & $4.903 * *$ & $4.306^{* *}$ \\
\hline & & & & $(2.497)$ & $(2.278)$ & $(1.816)$ \\
\hline \multirow[t]{2}{*}{$\operatorname{Ln} \cup C(t-1)$} & & & & -3.259 & -3.671 & -2.958 \\
\hline & & & & $(2.597)$ & $(2.562)$ & $(1.967)$ \\
\hline Ln FBCF & & & & & $-4.455^{*}$ & -3.837 \\
\hline
\end{tabular}




\begin{tabular}{|c|c|c|c|c|c|c|}
\hline & & & & & (2.485) & $(2.912)$ \\
\hline \multirow[t]{2}{*}{ Ln Juros } & & & & & & -0.170 \\
\hline & & & & & & (0.502) \\
\hline \multirow[t]{2}{*}{ Constante } & $9.070^{*}$ & $-35.69 * *$ & $-31.94 * *$ & 0.279 & -9.905 & -11.30 \\
\hline & (5.388) & $(18.02)$ & $(16.02)$ & $(14.82)$ & (16.33) & (14.98) \\
\hline $\begin{array}{l}\text { Número de } \\
\text { instrumentos }\end{array}$ & 12 & 23 & 24 & 29 & 30 & 34 \\
\hline AR (2) & 0,258 & 0,260 & 0,260 & 0,325 & 0,358 & 0,350 \\
\hline Teste de Hansen & 0,105 & 0,156 & 0,154 & 0,355 & 0,503 & 0,508 \\
\hline Lag dos instrumentos & 2 & 2 & 2 & 4 & 4 & 4 \\
\hline
\end{tabular}

Fonte: Elaboração própria.

Nota 1: Erros-padrão entre parênteses. ${ }^{* *} p<0.01,{ }^{* *} p<0.05,{ }^{*} p<0.1$.

Nota 2: Foi utilizada a correção para erros-padrão proposta por Windmeijer (2005).

Tabela 5: System GMM (Variável Dependente: Média-baixa Tecnologia (In))

\begin{tabular}{|c|c|c|c|c|c|c|}
\hline Variáveis & (1) & (2) & (3) & (4) & (6) & (7) \\
\hline \multirow[t]{2}{*}{ Ln Mebaixa Tec (t-1) } & $0.707^{* * *}$ & $0.353^{* *}$ & $0.395 * * *$ & 0.188 & $0.367^{* *}$ & 0.322 \\
\hline & $(0.103)$ & $(0.141)$ & $(0.116)$ & $(0.285)$ & $(0.181)$ & (0.243) \\
\hline \multirow[t]{2}{*}{ Ln Câmbio_BS } & -0.206 & -0.799 & 0.296 & -1.294 & -0.466 & 1.044 \\
\hline & $(1.052)$ & (0.593) & (0.883) & $(1.336)$ & (1.681) & (2.036) \\
\hline \multirow[t]{2}{*}{ Ln Câmbio_BS (t-1) } & 0.220 & 0.692 & -0.274 & -1.348 & -1.128 & -4.339 \\
\hline & (0.484) & $(0.534)$ & (0.735) & $(1.221)$ & (1.205) & (3.391) \\
\hline \multirow[t]{2}{*}{ Ln PIBparc } & & $1.730^{* *}$ & 1.627 & 0.610 & 0.345 & -0.0396 \\
\hline & & $(0.876)$ & (1.149) & $(1.548)$ & (1.358) & (1.328) \\
\hline \multirow{2}{*}{ Ln Ipcomm } & & & -0.518 & $-2.741^{*}$ & -0.00432 & 2.600 \\
\hline & & & (1.078) & $(1.478)$ & $(2.162)$ & $(2.131)$ \\
\hline \multirow[t]{2}{*}{$\operatorname{Ln} \cup C$} & & & & $2.925^{*}$ & $4.704 * *$ & $6.195 * * *$ \\
\hline & & & & $(1.609)$ & $(2.357)$ & $(1.891)$ \\
\hline \multirow[t]{2}{*}{$\operatorname{Ln} \cup C(t-1)$} & & & & -1.826 & $-3.599 *$ & $-4.863 * * *$ \\
\hline & & & & $(1.916)$ & (2.108) & $(1.771)$ \\
\hline \multirow[t]{2}{*}{ Ln FBCF } & & & & & -2.624 & $-5.589 *$ \\
\hline & & & & & $(1.785)$ & (2.919) \\
\hline \multirow[t]{2}{*}{ Ln Juros } & & & & & & 0.859 \\
\hline & & & & & & $(0.672)$ \\
\hline \multirow[t]{2}{*}{ Constante } & 5.435 & -14.15 & -11.63 & 17.84 & 14.81 & 28.91 \\
\hline & $(4.487)$ & $(14.70)$ & (12.31) & (18.25) & (20.64) & (21.92) \\
\hline $\begin{array}{l}\text { Número de } \\
\text { instrumentos }\end{array}$ & 12 & 21 & 24 & 29 & 30 & 34 \\
\hline$A R(2)$ & 0,721 & 0,588 & 0,586 & 0,554 & 0,358 & 0,276 \\
\hline Teste de Hansen & 0,231 & 0,458 & 0,438 & 0,433 & 0,503 & 0,514 \\
\hline Lag dos instrumentos & 2 & 3 & 2 & 4 & 4 & 3 \\
\hline
\end{tabular}

Fonte: Elaboração própria.

Nota 1: Erros-padrão entre parênteses. ${ }^{* *} p<0.01,{ }^{*} p<0.05,{ }^{*} p<0.1$.

Nota 2: Foi utilizada a correção para erros-padrão proposta por Windmeijer (2005). 
Tabela 6: System GMM (Variável Dependente: Baixa Tecnologia (In))

\begin{tabular}{|c|c|c|c|c|c|c|}
\hline Variáveis & (1) & (2) & (3) & (4) & (5) & (6) \\
\hline \multirow[t]{2}{*}{ Ln Baixa Tec (t-1) } & $0.603^{* *}$ & 0.172 & 0.214 & 0.448 & $0.724^{*}$ & $0.683^{* *}$ \\
\hline & $(0.295)$ & $(0.269)$ & $(0.424)$ & $(0.332)$ & $(0.385)$ & (0.323) \\
\hline \multirow[t]{2}{*}{ Ln Câmbio_BS } & -0.703 & -0.0351 & 0.0564 & 0.0121 & 0.348 & 0.172 \\
\hline & $(0.544)$ & $(0.716)$ & $(1.040)$ & $(0.743)$ & $(0.751)$ & $(0.474)$ \\
\hline \multirow[t]{2}{*}{ Ln Câmbio_BS (t-1) } & 0.112 & -0.140 & -0.0847 & 0.177 & 0.468 & 0.398 \\
\hline & $(0.528)$ & (0.993) & $(0.715)$ & $(0.414)$ & $(0.850)$ & (0.664) \\
\hline \multirow[t]{2}{*}{ Ln PIBparc } & & 1.090 & 1.012 & 1.563 & 0.706 & 0.253 \\
\hline & & $(1.180)$ & $(1.487)$ & $(1.749)$ & (0.599) & $(0.957)$ \\
\hline \multirow[t]{2}{*}{ Ln Ipcomm } & & & 0.111 & 0.459 & $1.111 *$ & 1.050 \\
\hline & & & (1.019) & $(0.804)$ & $(0.631)$ & (0.863) \\
\hline \multirow[t]{2}{*}{ Ln UC } & & & & 0.255 & 0.313 & 0.718 \\
\hline & & & & $(0.572)$ & (0.815) & $(1.051)$ \\
\hline \multirow[t]{2}{*}{$\operatorname{Ln} \cup C(t-1)$} & & & & -0.688 & -0.457 & -0.657 \\
\hline & & & & $(1.104)$ & $(0.748)$ & (0.949) \\
\hline \multirow[t]{2}{*}{ Ln FBCF } & & & & & -0.633 & -0.761 \\
\hline & & & & & $(0.941)$ & (1.196) \\
\hline \multirow[t]{2}{*}{ Ln Juros } & & & & & & -0.000211 \\
\hline & & & & & & (0.198) \\
\hline \multirow[t]{2}{*}{ Constante } & $10.40^{*}$ & 0.302 & -0.460 & -11.37 & -9.301 & -1.689 \\
\hline & (5.939) & (17.44) & (10.69) & $(21.31)$ & (10.99) & (16.95) \\
\hline $\begin{array}{l}\text { Número de } \\
\text { instrumentos }\end{array}$ & 12 & 23 & 24 & 35 & 33 & 31 \\
\hline AR (2) & 0,639 & 0,968 & 0,990 & 0,866 & 0,803 & 0,821 \\
\hline Teste de Hansen & 0,046 & 0,161 & 0,171 & 0,906 & 0,647 & 0,498 \\
\hline Lag dos instrumentos & 2 & 2 & 2 & 2 & 3 & 4 \\
\hline
\end{tabular}

Fonte: Elaboração própria.

Nota 1: Erros-padrão entre parênteses. ${ }^{* *} p<0.01,{ }^{*} p<0.05,{ }^{*} p<0.1$.

Nota 2: Foi utilizada a correção para erros-padrão proposta por Windmeijer (2005).

Tabela 7: System GMM (Variável Dependente: Produtos Não Industriais (In))

\begin{tabular}{lcccccc}
\hline \multicolumn{1}{c}{ Variáveis } & $(1)$ & $(2)$ & $(3)$ & $(4)$ & $(5)$ & $(7)$ \\
\hline Ln Não Ind (t-1) & $0.929^{* * *}$ & 0.080 & 0.177 & $0.574^{* * *}$ & $0.572^{* * *}$ & $0.559^{* * *}$ \\
& & & & & & \\
& $(0.0887)$ & $(0.171)$ & $(0.219)$ & $(0.170)$ & $(0.174)$ & $(0.179)$ \\
Ln Câmbio_BS & $-0.628^{*}$ & -0.195 & 0,041 & -0.0723 & 0,626 & 0.613 \\
& $(0.378)$ & $(0.260)$ & $(0.494)$ & $(0.750)$ & $(1.098)$ & $(0.862)$ \\
\hline Ln Câmbio_BS (t-1) & 0.446 & $-0,570$ & -0.300 & $0.636^{*}$ & 0.527 & -0.478 \\
& $(0.425)$ & $(0.387)$ & $(0.522)$ & $(0.358)$ & $(0.388)$ & $(0.969)$ \\
Ln PIBparc. & & $2.687^{* * *}$ & $2,188^{* * *}$ & 1.660 & $2,518^{* *}$ & 1.648
\end{tabular}


Ln Ipcomm

Ln UC

$\operatorname{Ln} \cup C(t-1)$

$\begin{array}{lll}0.873 & -0.724 & 0.218\end{array}$

Ln FBCF

Ln Juros

Número de instrumentos

$14 \quad 15$

AR (2)

0,169

Fonte: Elaboração própria.

Nota 1: Erros-padrão entre parênteses. ${ }^{* *} p<0.01,{ }^{* *} p<0.05,{ }^{*} p<0.1$.

Nota 2: Foi utilizada a correção para erros-padrão proposta por Windmeijer (2005).

\section{Abordagem teórica do Modelo Dinâmico de Dados em Painel e do Câmbio Balassa-Samuelson}

Com base em Cameron e Trivedi (2005, cap. 22), considere a Equação A.1, em que $\Phi<1$.

$$
y_{i t}=\phi y_{i, t-1}+\beta x_{i t}^{\prime}+\alpha_{i}+\varepsilon_{i t}
$$

Considerando a tendência temporal, $y_{i t}$ é induzido de maneira direta por $y_{i, t-1}$ e pelo efeito indireto de $\alpha_{1}$. Considerando $\beta=0$, temos que $\mathrm{E}\left[y_{i t} \mid y_{i, t-1}, \alpha_{i}\right]$ $=\phi y_{i, t-1}+\alpha_{i}$, e a correlação de $\left[y_{i t}, y_{i, t-1} \mid \alpha_{i}\right]=\phi$. Como $\alpha_{1}$ é um valor não conhecido, $\mathrm{E}\left[y_{i t} \mid y_{i, t-1}\right]=\phi y_{i, t-1}+\mathrm{E}\left[\alpha_{i} \mid y_{i, t-1}\right]$ e a correlação de $\left[y_{i t} \mid y_{i, t-1}\right] \neq \phi$. Assim, a Corr $\left[y_{i t} \mid y_{i, t-1}\right]=\phi+\operatorname{Corr}\left[\alpha_{i} \mid y_{i, t-1}\right]$.

Anderson e Hsiao (1981) propõem a estimação por meio de variáveis instrumentais, conforme Equação A.2, sendo $y_{i, t-2}$ um instrumento para $\left(y_{i, t-1}-y_{i, t-2}\right)$.

$$
y_{i t}-y_{i, t-1}=\phi y_{i, t-1}-y_{i, t-2}+\beta^{\prime}\left(x_{i t}^{\prime}-x_{i, t-1}^{\prime}\right)+\varepsilon_{i t}-\varepsilon_{i, t-1}
$$

Arellano e Bond (1991) propõem uma estimação por meio da primeira diferença (Equação A.3).

$$
\Delta y_{i t}=\phi \Delta y_{i, t-1}+\beta \Delta x_{i t}^{\prime}+\Delta \alpha_{i}+\Delta \varepsilon_{i t}
$$

A principal suposição é que $\Delta u_{i t}$ é correlacionado com $\Delta y_{i, t-1}$, mas não correlacionado com $\Delta u_{i, t-k}$ para $\mathrm{k} \geq 2$, sendo $u_{i t}=\alpha_{i}+\varepsilon_{i t}$ Em outras palavras, a primeira diferença dos erros $\Delta \varepsilon_{i t}$ são correlacionados em AR (1), mas não em ordens $\geq 2$. Blun- 
dell e Bond (1998) propõem este estimador utilizando a primeira diferença como um instrumento para a equação em nível, sendo esse o estimador System GMM ${ }^{24}$.

Neste artigo foi proposta uma forma diferente de taxa real de câmbio dentro do território nacional, adaptando-se para as UFs a metodologia proposta por Rodrik (2008). Essa visa ajustar a taxa de câmbio pela paridade do poder de compra das UFs, bem como pelos níveis de preços relativos entre setores tradeables e non-tradeables. Rodrik (2008) indica três passos para calcular essa taxa de câmbio. O primeiro ocorre pela razão da taxa de câmbio pelo fator de conversão da paridade do poder de compra (PPP).

$$
\ln T R C_{i t}=\ln \left(T C_{i t} / P P P_{i t}\right)
$$

em que $\mathrm{TC}^{25}$ representa a taxa efetiva real de câmbio e TRC a proxy da taxa efetiva real de câmbio de cada UF. Para a conversão da PPP, Rodrik (2008) indica uma base de dados ${ }^{26}$ em que esses valores já estão calculados para o nível de países. Aqui, optou-se por utilizar uma proxy simplificadora ${ }^{27}$, que leva em conta a diferença de preços de uma cesta de consumo ${ }^{28}$ nas capitais ${ }^{29}$ das UFs, ponderado pelo peso dessa cesta nos gastos domiciliares ${ }^{30}$.

Considerando o efeito Balassa-Samuelson, de que locais com maior renda, principalmente em setores tradeables, tendem a apresentar preços maiores em bens non treadebles, torna-se útil um ajuste nos dados. Isso pode ser feito por meio da captação dos efeitos que a elevação na renda pode apresentar sobre a TRC.

$$
\operatorname{lnTRC} C_{i t}=\alpha+\beta \ln P I B p c_{i t}+f_{t}+\varepsilon_{i t}
$$

em que PIBpcé o PIB per capita de cada UF, $f_{t}$ é o efeito fixo e $\varepsilon_{i t}$ o termo de erro. O painel com efeitos fixos captou um $\beta$ de - 0,200 (com erros-padrão de 0,023 e estatística $\mathrm{z}$ de -8.44), indicando que $10 \%$ de aumento na renda das UFs tende a causar uma valorização de $2 \%$ na TRC. Assim, para se chegar à taxa efetiva real de câmbio ajustada pelo efeito Balassa-Samuelson para as UFs, utiliza-se a Equação A.6.

$$
\ln C \text { âmbio_BS } i t=\ln T R C_{i t}-\ln T R C_{i t}
$$

em que $\ln T R C_{l t}$ é o valor estimado pela Equação A.5.

\footnotetext{
${ }^{24}$ Este estimador constrói um sistema de duas equações, uma original e outra transformada.

${ }^{25}$ TC varia apenas no tempo, mas não entre as UFs.

${ }^{26}$ Penn World Tables.

${ }^{27}$ A base de dados não contempla algumas UFs, sendo considerados valores médios para esses casos.

${ }^{28}$ Como itens da cesta de consumo, utilizaram-se os produtos de uma cesta básica.

${ }^{29}$ As bases de dados estaduais são restritas, sendo necessário fazer algumas simplificações, bem como utilizar os dados da capital de cada estado como proxy.

${ }^{30}$ Como proxy do peso dos produtos nos gastos domiciliares, foi utilizado o tempo necessário de trabalho para a aquisição de uma cesta básica em cada capital.
} 